\title{
Evolution of supply chain ripple effect: a bibliometric and meta-analytic view of the constructs
}

\author{
Deepa Mishra ${ }^{a}$, Yogesh K. Dwivedi ${ }^{\mathrm{b}}$, Nripendra P. Rana ${ }^{\mathrm{c}}$ and Elkafi Hassini ${ }^{\mathrm{d}}$ \\ andian Institute of Management Amritsar, Amritsar, India; 'Emerging Markets Research Centre (EMaRC), School of \\ Management, Swansea University Bay Campus, Wales, UK; 'School of Management, University of Bradford, Bradford, UK; \\ ${ }^{\mathrm{d} D e G r o o t e}$ School of Business, McMaster University, Hamilton, Canada
}

\begin{abstract}
In the broad sphere of Operations Management, Supply Chain Risk Management (SCRM) is a significant area of interest for both academics and practitioners. As SCRM has transitioned from an emerging topic to a growing research area, there is a need to review existing literature in order to ascertain development in this area. There are many literature reviews on this topic, however there is lack of an extensive review using network analysis and meta-analysis within SCRM context including ripple effect. To address this gap, we performed a review of 2,564 articles published in peer-reviewed academic journals from 1976 to December 2018. First, we apply a network analysis tool on 2,564 articles and identify emerging research clusters. Second, to conduct meta-analysis, we collated empirical results from the studies identified. Of those 2,564 articles, 42 studies were empirical in nature including 29 studies that used a range of different constructs with appropriate correlation values required for performing meta-analysis. Through this study, we contribute to the literature on SCRM by discussing the challenges of current research, but more importantly, by identifying and proposing five research clusters and future research directions. Finally, the paper acknowledges the theoretical contribution, the limitations of this study, and suggests further research directions.
\end{abstract}

Keywords: supply chain risk management; ripple effect, network analysis; meta-analysis; literature review

\section{Introduction}

Today's business environment is characterised by shorter product life cycles, uncertain customer demand, vulnerability to supply disruptions and innovative information technologies (Ivanov, Sokolov and Dolugi, 2014; Rangel et al., 2015; Macdonald et al. 2018; Dolgui et al. 2018). This has created fierce competition between firms, and thus, raised the performance expectations of their supply chains. In particular, these supply chains are expected to respond quickly, efficiently and effectively to the changes in market conditions (Lee, 2004; Lavastre et al. 2014; Ivanov et al. 2017). However, this transition in nature of supply chains makes them vulnerable to various risks (Christopher and Towill, 2002), and it becomes difficult to anticipate the type and nature of uncertain developments as the modern supply chains are complicated and interrelated. This makes supply chain risk management (SCRM) an attractive area of research that refers to the overall management of risks ranging across the entire spectrum of a supply chain (Qazi et al., 2017) by developing procedures and techniques for identifying, assessing and mitigating risks in supply chains (Narasimhan and Talluri, 2009). 
In general, supply chain risk is characterized as "the likelihood of an adverse and unexpected event that can occur and either directly or indirectly result in a supply chain disruption" (Garvey et al., 2015, pp. 619). Although various studies on supply chain disruption management may differ in their methodology or approach, their core concept remains the same i.e., disruption, its impact on operational and strategic economic performance and stabilization and recovery policies (Dolgui et al., 2018). Thus, most of these studies analysed the way in which one or several changes ripple across the supply chain and affect its performance, which is commonly referred to as the ripple effect in the supply chain (Ivanov, Sokolov and Pavlov, 2014). It is created when the disruption cannot be restricted to a single part of the supply chain and cascades downstream to impact supply chain performance (Ivanov et al. 2014; 2018). Since this ripple effect might result in lower revenues, delivery delays, loss of market share, and decrease in stock return, it is vital to understand and evaluate ripple effect in a supply chain. Moreover, supply chain risks could happen randomly and distinctly like natural disasters and disruptive technologies, and inevitably and continuously like exchange rate fluctuations and market forecasting, and their impacts can be restricted in a specific area or spread along the entire supply chain (Wu et al., 2015; Fan et al., 2017; Ivanov, 2018). In order to control and minimize the negative consequences of these risks, a significant amount of work has been done in the area of SCRM by both academicians and practitioners.

In the last decade, around ten articles have appeared that review the literature on SCRM. First, Tang (2006) reviewed quantitative models that deal with supply chain risks by focussing on the time frame between 1964 and 2005, and classified more than 200 articles based on supply, demand, product and information management. Second, Rao and Goldsby (2009) reviewed 55 journal articles published in the past decade, i.e., 1998-2008, and synthesised the literature by proposing a typology of risk factors. With the aim to investigate the research development in SCRM, Tang and Musa (2011) adopted the citation and co-citation analysis technique to review 138 journal articles published between 1995 and mid 2008 and identified and classified the potential risk associated with material, cash and information flow in supply chains. Next, in 2012, two reviews were conducted - one by Colicchia and Strozzi (2012) who used the citation analysis technique to review 55 articles published between 1994 and 2010, and identified the evolutionary patterns and emerging trends in SCRM, and second by Sodhi, Son, and Tang (2012) who reviewed 31 journal articles published between 1998 and 2010 with the aim to formulate their own view on the diverse literature on SCRM. 
In 2015, three reviews were conducted: (i) Heckmann et al. (2015) reviewed the existing approaches for quantitative SCRM and identified the core characteristics that are used to define, quantify and model supply chain risk; (ii) Ho et al. (2015) reviewed and synthesized the extant literature in SCRM published between 2003 and 2013 to present the research developments in supply chain risk definitions, risk types, risk factors and risk management and mitigation strategies; and (iii) Fahimnia et al. (2015) used bibliometric and network analysis tools to review articles published between 1976 and 2013 in top journals and identified research areas that have provided the field with the foundational knowledge, concepts, theories, tools, and techniques. Recently, Kilubi (2016) applied a bibliometric tool to analyse 32 most co-cited articles in the SCRM area published in 16 academic journals from 2000 to 2011 using multivariate statistical techniques. More recently, Surya et al. (2017) reviewed 343 research articles published between 2004 and 2014 to analyse and synthesize the extant SCRM literature from the perspective of the risk management process.

While the above-mentioned reviews make significant contributions to the SCRM area of research, there are a few knowledge gaps that motivate us to carry out this study. First, most of these review articles emphasize only on a specific area of SCRM, for instance, risk classification (Tang and Musa, 2011; Prakash et al., 2017), risk factor analysis (Rao and Goldsby, 2009), risk management methods (Tang, 2006a), research gap identification (Colicchia and Strozzi, 2012), or risk management process (Surya et al., 2017). Hence, our review focuses on all the aspects of SCRM, including the ripple effect. Second, most of the literature reviews have been done by adopting the techniques of citation analysis, co-citation analysis or bibliometric and network analysis. None of them has considered the technique of meta-analysis which specifically focuses on empirical studies. Third, these review articles have generally been conducted for a period of around 10 years, such as, 1998-2008 (Rao and Goldsby, 2009), 1998-2010 (Sodhi et al., 2012), 2003-2013 (Ho et al., 2015), 2004-2014 (Surya et al., 2017). Only Fahimnia et al. (2015) considered articles published between 1976 and 2013, but they employed the technique of bibliometric and network analysis to systematically review quantitative and analytical models for managing supply chain risks, thereby focussing on only one aspect of methodology. In particular, it is worth noting that none of the existing reviews have focused on empirical approaches to SCRM. In order to fill these gaps, this paper presents a comprehensive review of all relevant journal articles in the area of SCRM appearing between 1976 and December 2018. We adopt a data clustering method using Gephi software to generate five emerging clusters. Based on the clusters, we propose various future directions of research. Our work also analyses empirical studies published in this area and identifies 
the possible relationship among various constructs.

The rest of the paper is organized as follows. In the next section, we cover the literature on supply chain risk definitions, sources, mitigation strategies and ripple effect. We present the research methodology in the third section which is followed by data analysis, including network and metaanalysis. In the fifth section, we highlight the contribution of our study to theory and practice and identify future research directions. Finally, the paper concludes in the sixth section.

\section{Literature review}

Almost every business process and decision is exposed to the danger of risk. So, it is essential to continuously monitor and manage risks as lack of proper assessments and judgements may generate unpredicted developments and create adverse effects if not detected on time (Colicchia and Strozzi, 2012). The failure to successfully manage risk in supply chains not only creates a negative impact on organizations, such as, sharp downward trend in share prices, but also creates a clash among the stakeholders (Hendricks and Singhal, 2005). In fact, this failure to effectively manage risks can reduce product quality, damage property and equipment, effect the reputation in the eyes of customers, suppliers and the wider public, and delivery delays (Cousins et al., 2004).

\subsection{Definitions of supply chain risk}

Several definitions for supply chain risks have been proposed in the literature. In this direction, the first attempt was made by March and Shapira (1987) who contemplate risk as the "variation in the distribution of possible supply chain outcomes, their likelihood, and their subjective values"(pp. 1404). From a supply chain perspective, these risks refer to the possibility and effect of mismatch between supply and demand. A popular definition that has been adopted by several researchers is that of Juttner et al. (2003): "anything that disrupts or impedes the information, material or product flows from original suppliers to the delivery of the final product to the ultimate end user"'(pp. 222). It is evident that this definition specifically focused on the risk occurring in the information, material or product flows. In a similar vein, Zsidisin (2003) focused on the risk originating from the supplier side, and defined supply risk "as the probability of an incident associated with inbound supply from an individual supplier failure or the supply market occurring, in which its outcomes result in the inability of the purchasing firm to meet customer demand or causes threats to customer life and safety" (pp. 222).

\subsection{Sources of supply chain risk}


A number of classifications for the sources of supply chain risks are available in literature. Some studies classify supply chain risks based on their negative impact on the firms - macro risks and micro risks (Ho et al., 2015). Macro risks refer to the natural and man-made risks that have adverse effects on companies, while micro-risks refer to the risks that originate from the internal activities of the companies or relationships with their partners. These risks have also been identified as disruption and operational risks by Tang (2006), catastrophic and operational by Sodhi et al. (2012), and value at-risk and miss-the target by Ravindran et al. (2010). Others have classified risks based on whether they are internal or not necessarily internal to the supply chain - internal risks and external risks. Wagner and Bode (2008) considered demand and supply side risks as internal risks whereas, regulatory, legal and bureaucratic; infrastructure; and catastrophic were considered as external risks. Another categorization of supply chain risks has been provided by Juttner et al. (2003), Christopher and Peck (2004), and Lin and Zhou (2011). They considered three categories - organizational risk or internal risk (e.g. process and control risks), network-related risk or risk within the supply chain (e.g. demand and supply risks), and environmental risk or risk in the external environment (e.g. natural disasters, war and terrorism and political instability).

Kleindorfer and Saad (2005) identified the three sources disruption risk as operational contingencies focussing on equipment malfunctions and systemic failures; natural hazards such as, earthquakes, hurricanes and storms; and terrorism and political instability. Further, Manuj and Mentzer (2008) provided four categories of risks-supply, demand, operational and security risks. Moreover, there are various other factors that play a significant role in the proper functioning of the supply chain. For instance, information technology (Chopra and Sodhi, 2004), transportation (Wu et al., 2006) and financial systems (Hiles and Barnes, 2001; Christopher and Peck, 2004). The risks originating in these systems have been categorized as infrastructural risks by Ho et al. (2015).

Table 1: Definition and supply chain risk sources

\begin{tabular}{|l|l|}
\hline Supply chain risk definitions & Literature \\
\hline $\begin{array}{l}\text { Variation in the distribution of possible supply chain outcomes, } \\
\text { their likelihood, and their subjective values }\end{array}$ & $\begin{array}{l}\text { March and Shapira (1987, pp. } \\
1404)\end{array}$ \\
\hline $\begin{array}{l}\text { The probability of an incident associated with inbound supply } \\
\text { from individual supplier failures or the supply market } \\
\text { occurring, in which its outcomes result in the inability of the } \\
\text { purchasing firm to meet customer demand or cause threats to } \\
\text { customer life and safety }\end{array}$ & Zsidisin (2003, pp. 222) \\
\hline $\begin{array}{l}\text { Any risk for the information, material and product flows from } \\
\text { original suppliers to the delivery of the final product for the } \\
\text { end user }\end{array}$ & $\begin{array}{l}\text { Jütner, Peck, and Christopher } \\
\text { (2003, pp. 200) }\end{array}$ \\
\hline
\end{tabular}




\begin{tabular}{|c|c|}
\hline $\begin{array}{l}\text { The negative deviation from the expected value of a certain } \\
\text { performance measure, resulting in negative consequences for } \\
\text { the focal firm }\end{array}$ & Wagner and Bode (2006, pp. 303) \\
\hline $\begin{array}{l}\text { The potential variation of outcomes that influence the decrease } \\
\text { of value added at any activity cell in a chain }\end{array}$ & $\begin{array}{l}\text { Bogataj and Bogataj (2007, pp. } \\
\text { 291) }\end{array}$ \\
\hline $\begin{array}{l}\text { An individual's perception of the total potential loss associated } \\
\text { with the disruption of supply of a particular purchased item } \\
\text { from a particular supplier }\end{array}$ & $\begin{array}{l}\text { Ellis, Henry, and Shockley (2010, } \\
\text { pp. 36) }\end{array}$ \\
\hline Supply chain risk sources & Literature \\
\hline $\begin{array}{l}\text { Strategic, Financial, Operational, Commercial and Technical } \\
\text { risks }\end{array}$ & Hiles and Barnes, 2001 \\
\hline Process, Control, Demand, Supply and Environmental & Christopher and Peck (2003) \\
\hline $\begin{array}{l}\text { Disruptions, Delays, Systems, Forecast, Intellectual property, } \\
\text { Procurement, Receivables, Inventory and Capacity }\end{array}$ & Chopra and Sodhi, (2004) \\
\hline Operational, Natural and terrorism and Political instability & Kleindorfer and Saad (2005) \\
\hline Disruption and Operational risks & Tang (2006) \\
\hline Supply, Demand, Operational and Security risk & Manuj and Mentzer (2008) \\
\hline $\begin{array}{l}\text { Internal (eg. demand and supply side) and External (eg. } \\
\text { regulatory, legal and bureaucratic, infrastructure; and } \\
\text { catastrophic) }\end{array}$ & Wagner and Bode (2008) \\
\hline Value at-risk and Miss-the target & Ravindran et al. (2010) \\
\hline Catastrophic and Operational & Sodhi et al. (2012) \\
\hline Macro and Micro risks & Ho et al. (2015) \\
\hline $\begin{array}{l}\text { Organizational risk or internal risk (e.g. process and control } \\
\text { risks), Network-related risk or risk within the supply chain (e.g. } \\
\text { demand and supply risks), and Environmental risk or risk in the } \\
\text { external environment (e.g. natural disasters, war and terrorism } \\
\text { and political instability). }\end{array}$ & $\begin{array}{l}\text { Juttner et al. (2003), Christopher } \\
\text { and Peck (2004), Lin and Zhou } \\
\text { (2011) }\end{array}$ \\
\hline
\end{tabular}

\subsection{Risk Mitigation strategies}

Numerous studies have proposed and categorized risk mitigation strategies as a way to enhance competitive advantage and organizational performance (Wagner and Bode, 2008; Hallikas et al., 2004). One of the most important and highly cited typology was given by Choi and Liker (1995) who categorized risk mitigation strategies as - process-oriented strategies and buffer-oriented strategies. Process-oriented strategies emphasize on process rather than outcomes, and by implementing them, managers may avoid the risks by focusing on its causes (Anderson and Oliver 1987) whereas, buffer-oriented strategies emphasize on outcomes rather than process, and by employing buffers, firms can minimize the possibility and impact of adverse events (Zsidisin, 2003). Later on, Mullai (2009) proposed four categories for risk mitigation strategies - avoidance, 
reduction, transfer and acceptance. Adopting resource dependence theory, Bode et al. (2011) proposed buffering and bridging as the two generic but separate risk-mitigation strategies. They noted that buffering and bridging are the two responses that can be generated by firms where, buffering is external while, bridging is internal to a current relationship. In addition, Manuj et al. (2014) proposed four specific strategies to minimize global supply chain risks - hedging, assuming strategy, postponement and speculation.

\subsection{Ripple effect in supply chain}

The concept of ripple effect is defined as disruption propagation in supply chain and its impact on supply chain performance in terms of sales, on-time delivery and profit (Ivanov, 2018 a, b, c; Ivanov et al., 2019a, b). It not only impacts the supply chain performance but might include lower revenue, market share, delivery delays and lower stock return (Hendricks and Singhal 2005). For instance, in 2011, Toyota lost its market leader position and was forced to redevelop supply chain coordination. Ripple effect is often referred to as "domino effect" or "snowball effect" and is mainly developed due to the complexity in supply chain and consequent pressure on speed and efficiency, thereby resulting in increase in number of industries world-wide, specifically, in industrial districts. Therefore, Ivanov et al. (2014) defined it as "the disruption propagation in the supply chain, impact of a disruption on supply chain performance and disruption-based scope of changes in supply chain structures and parameters". So, in order to manage these effects, lowfrequency-high-impact disruptions should be evaluated and understood through methodical elaborations.

\subsubsection{Ripple effect methodologies}

Recent studies on safeguarding supply chains from negative impacts of disruptions have mainly adopted two approaches - proactive and reactive. While proactive approach aims at protecting supply chain without considering recovery measures in design stage (Dolgui and Prodhon, 2007, Klibi et al. 2010, Dolgui et al., 2013, Aloulou et al., 2014, Snyder et al. 2016; Ivanov et al., 2016), reactive approach focusses on adjusting supply chain processes and structures when any disruption takes place (Knemeyer et al., 2009 ; Ivanov et al. 2016a, b; Ivanov et al. 2017b).

Researchers adopting mathematical optimization methodology have mainly applied mixed-integer programming or stochastic programming to study supply chain disruption. In mixed-integer programming, various impacts of disruptions on supply chain performance are revealed by considering constraints on supply chain design and planning as mathematical problems. It has 
been used to find optimal supply chain design by assigning customers to locations and minimizing total supply chain costs (Snyder and Daskin, 2005), create a totally reliable back-up supplier (Lim et al., 2010), devise a joint inventory location model (Chen et al., 2011), compare the impact of under- and over-estimation of disruptions on the total supply chain costs (Lim et al., 2013), analyse the situation of multiple products and periods with back-up suppliers and reserved capacity (Rafiei et al., 2013), explore resilience in correlated disruptions (Hasani and Khosrojerdi, 2016), and identify the most profitable network and mitigation policy in terms of emergency stock, back-up capacity and multiple sourcing (Rezapour et al., 2017). Unlike the above approach, stochastic programming is scenario based and its objective function involves both first stage and expected second stage performance. In this type of modelling, demand is usually considered as an uncertain parameter (Tsiakis et al., 2001; Santosa et al., 2005; Goh et al., 2007), but in some cases, facility disruptions and capacity expansion costs have also been considered uncertain (Azaron et al., 2008). It has been used to integrate supplier selection, order quantity allocation and customer order scheduling during SC disruption risks (Sawik, 2013) and for supplier selection and order allocation problem under operational and disruption risks (Torabi et al., 2015).

Another methodology that has been widely used to analyse the ripple effect in the supply chain is simulation (Ivanov, 2019). The benefit of conducting simulation-based study is that it can handle complex problems involving situations which change over time, and thus, such studies when conducted on ripple effect can deal with time-dependent and gradual disruption duration, duration of recovery measures and capacity degradation and recovery (Ivanov 2017 a, b). Researchers have simulated the ripple effect in supply chains using system dynamics (Wilson, 2007; Ivanov, 2019), agent-based simulation (Xu et al., 2014) and discrete-event simulation (Carvalho et al., 2012; Schmitt and Singh, 2012; Ivanov et al., 2017a, b; Ivanov, Pavlov, Pavlov and Sokolov, 2017). Further, studies adopting control theoretic approach to study ripple effect were conducted wherein optimal-program control and feedback control were combined to describe ripple effect (Ivanov et al., 2014a; Pavlov et al., 2017; Pavlov et al., 2019), linear programming and optimal control were combined to reconfigure transportation when disruption occurs (Ivanov et al., 2013), multi-period and multi-commodity supply chain was designed considering structural dynamics (Ivanov et al, 2014b), hybrid optimization-control (Pavlov et al., 2017) model was used to develop an approach which allows simultaneous analysis of performance impact in a simulation (Ivanov et al., 2016b) by keeping into account disruption duration and recovery costs (Ivanov et al., 2016a).

\subsubsection{Ripple effect mitigation strategies}


In order to maintain an effective and efficient supply chain, it needs to be protected from disturbances and disruptions, thereby making it stable, robust and resilient. Recent literature (Hosseini et al., 2019; Ivanov et al., 2017a, b; Ivanov and Dolgui, 2018; Ivanov et al., 2018; Ivanov and Sokolov, 2019) has focussed on these two fundamental concepts of robustness and resilience as a way to analyse supply chain performance. A supply chain is said to be robust if it remains insensitive to negative impacts of disturbances and continues to operate with minimum impact on performance (Ivanov and Sokolov 2013; Han and Shin 2016; Dolgui et al., 2019). It is usually achieved by maintaining some redundancy in terms of structural diversification, flexible response options and system adaptation condition improvement. Although robustness keeps a supply chain safe by keeping proactive redundancy (such as buffer capacities, backup suppliers, or risk mitigation inventory) at the pre-disruption stage, it is equally important for a supply chain to be resilient, i.e., perform safely. As Aven (2017) pointed out, being resilient helps a supply chain to restore its functionality and performance whenever there is a change in the environmental conditions. Thus, resilient supply chain overcomes the drawback of traditional supply chains by incorporating redundancies (back up facilities, inventory and capacity flexibility) which create some flexibility at the proactive planning stage, that can be further utilized if any disruption erupts at the reactive control stage, and recover its performance (Ivanov and Sokolov, 2013 and Ivanov 2018b). Further, since resilience includes both proactive and reactive stages, it is important to integrate pro- and reactive decisions in order to increase supply chain resilience by making use of the collaboration between mitigation and contingency policies.

Researchers have also emphasized that the main causes of disruption risks are single sourcing, low risk mitigation inventory, over utilization of capacities, low-level safety technologies and missing contingency plans (Dolgui et al., 2018; Scheibi and Blackhurst, 2018). The impact of ripple effect on supply chain performance is primarily determined by availability of redundancies and the scope of recovery measures. In other words, it is important to focus on two critical factors: resistance and recovery, where resistance refers to supply chain's ability to avoid disruptions and minimize its impact by keeping redundancy, recovery requires activation of this redundancy along with reactive contingency plans (Sokolov et al., 2016). Consequently, design and planning stages must involve assessment and implementation of risk and supply chain resilience, while contingency plans, such as alternative suppliers or shipping routes, should be put into use immediately in the control stage. By doing so, supply chains can be quickly stabilized and recovered; thereby maintaining supply continuity and avoiding any long-term impact. 
Different methods to strengthen supply chains, with respect to mitigating uncertainty impacts and ensuring supply chain's robustness, have been studied in the literature. These robustness reserves might include material inventory, capacity buffers. Although increase in inventory, additional production capacities and alternative transportation methods or backup facilities would increase costs, it would lead to an increase in sales and service level, minimize the risk of perturbations and enhance on-time delivery, and also increase supply chain flexibility. However, to achieve resilience in supply chains, it is desirable to maintain a balance between robustness and flexibility, and thus, enhance performance at acceptable redundancy costs.

\section{Research methodology}

The first step was to define keywords so that the topic of the study is fully captured. So, we chose three combinations of keywords: Supply Chain* AND Risk*, Supply Chain Risk Management AND Risk*, Supply Chain AND Risk Management and Supply Chain Risk* AND Ripple Effect. Second, consistent with our aim to study and analyse the development of the SCRM field of research, we decided not to fix a particular time frame, rather all the articles published till December 2018 were considered appropriate to capture the growth in SCRM.

Third, to obtain a comprehensive database of the SCRM articles, we decided not to compromise on either quality or quantity, and thus focussed Web of Science (WoS). WoS containing approximately 18,200 journals that have an impact factor, thus fulfilling our objective to identify articles with the highest credibility. Now, coherent with our scope, we did not restrict our analysis to any specific journal and selected all the journals with articles containing the aforementioned keywords in "title, abstract, keywords". As a result of these choices, we identified a total of 8458 articles.

Fourth, we refined the initial results to emphasize on the quality of the sources, rather the content of the paper. In this regard, we excluded the duplicates as few articles may belong to more than one combination of keywords. This exclusion resulted in 7456 articles. We further focused on articles published in English peer-reviewed journals and, as pointed by Ramos- Rodriguez and Ruiz-Navarro (2004), we included scientific publications (articles and reviews) in business and management area and excluded the grey literature (i.e., conference paper, master's theses, doctoral dissertations, textbooks and news report). After this refinement, we obtained 2564 articles published in peer-reviewed academic journals from 1976 to December 2018. This dataset was then saved and utilized for two different types of analysis - network analysis and meta-analysis. In the 
former case, we saved the final dataset in RIS (Research Information Systems) format. In the latter case, we found 42 empirical studies that included only 29 studies using a range of different constructs with appropriate correlation values and the remaining articles were discarded from the meta-analysis.

Meta-analysis will be performed using a trial version of comprehensive meta-analysis software (the free trial version could be downloaded from https://www.meta-analysis.com), which was successfully used by researchers (i.e. Ismagilova et al., 2019; Rana et al., 2015) in the previous studies. As far as the computation of meta-analysis of varied correlations between a pair of variables is concerned, we used the sample size of each study for which the specific correlation is retrieved along with Pearson correlation between a pair of variable. If the study has used two different datasets and separate Pearson correlations for each dataset then we considered them as two separate studies. Likewise, if two different studies have used the same dataset and Pearson correlation, we took only one study and discarded the other duplicate study.

\section{Data analysis}

As described below, we performed data analysis in the following two ways: Network Analysis and Meta-Analysis.

\subsection{Network analysis}

Before conducting network analysis, we did bibliometric analysis using Bib Excel software which has the ability to handle data from WoS database and analyses it for further use during network analysis in Gephi software (Ramos-Rodríguez and Ruíz-Navarro, 2004). In Bib Excel, we entered data regarding authors, title, journal, publication year, keywords, affiliations, and references of shortlisted articles in RIS format, which was later converted to different formats during analysis. For identifying the most influential authors, the author field was extracted from the RIS data file and the frequency of occurrence of these authors was noted. It was found that Choi, Kumar and Cheng with 24, 21 and 19 publications, respectively, dominate the list, which was closely followed by Wagner with 18 publications, Govindan and Talluri each with 16, and Dolgui and Ivanov with 14 publications each. Similarly, regarding journals, we found that IJPE with 288 articles and IJPR with 233 articles are major contributors in this area, followed by EJOR with 172 articles.

Now for network analysis, the RIS data file was reformatted to a network graph dataset or .NET file using the Bib Excel software. The resulting file was then used as input for network analysis in 
the Gephi software that offers flexible visual aids, powerful filtering techniques, and has the ability to handle different data formats (Gephi, 2013).

As the name suggests, data clustering aims at making clusters of articles having the same characteristics and separating them from the ones with different characteristics (Radicchi et al., 2004). Thus, links of nodes within the same cluster are dense as compared to the nodes belonging in different clusters (Leydesdorff, 2011), and to measure the density of these links, Modularity Index (range between -1 and +1 ) is calculated in Gephi using the inbuilt Louvian algorithm (Blondel et al., 2008). For the purpose of this study, we applied Louvian algorithm to 514 nodes network, which resulted in five major clusters and the value of modularity index was found to be 0.11 , thereby reflecting a moderately strong relationship among the nodes of the same cluster. This relationship can also be seen from Figure 1 in which the density of nodes within the cluster is high as compared to the nodes of other clusters (Mishra et al., 2016a, b). Further, it is more likely that the papers cited together share the same area of interest (Hjorland, 2013). This means that a research area of a cluster can be identified by conducting a thorough analysis of the papers belonging to that cluster. In this study, we considered only the top publications of each cluster based on their co-citation PageRank because we found that the number of papers in each cluster is high (Mishra et al. 2016a). Table 2 shows the top publications of each cluster based on PageRank. To identify the research focus of these five clusters, we carefully analysed the content of the leading papers of each cluster. We found that cluster 1 mainly includes articles focussing on fundamental aspects of supply chain. For instance, identifying the right supply chain for the product, understanding the qualities (agility, alignment, and adaptability) needed for outperforming other supply chains, acknowledging purchasing as an important factor to avoid economic and political disruptions, and aligning supply chain strategies with demand and supply uncertainties so as to avoid any sort of disruption. 


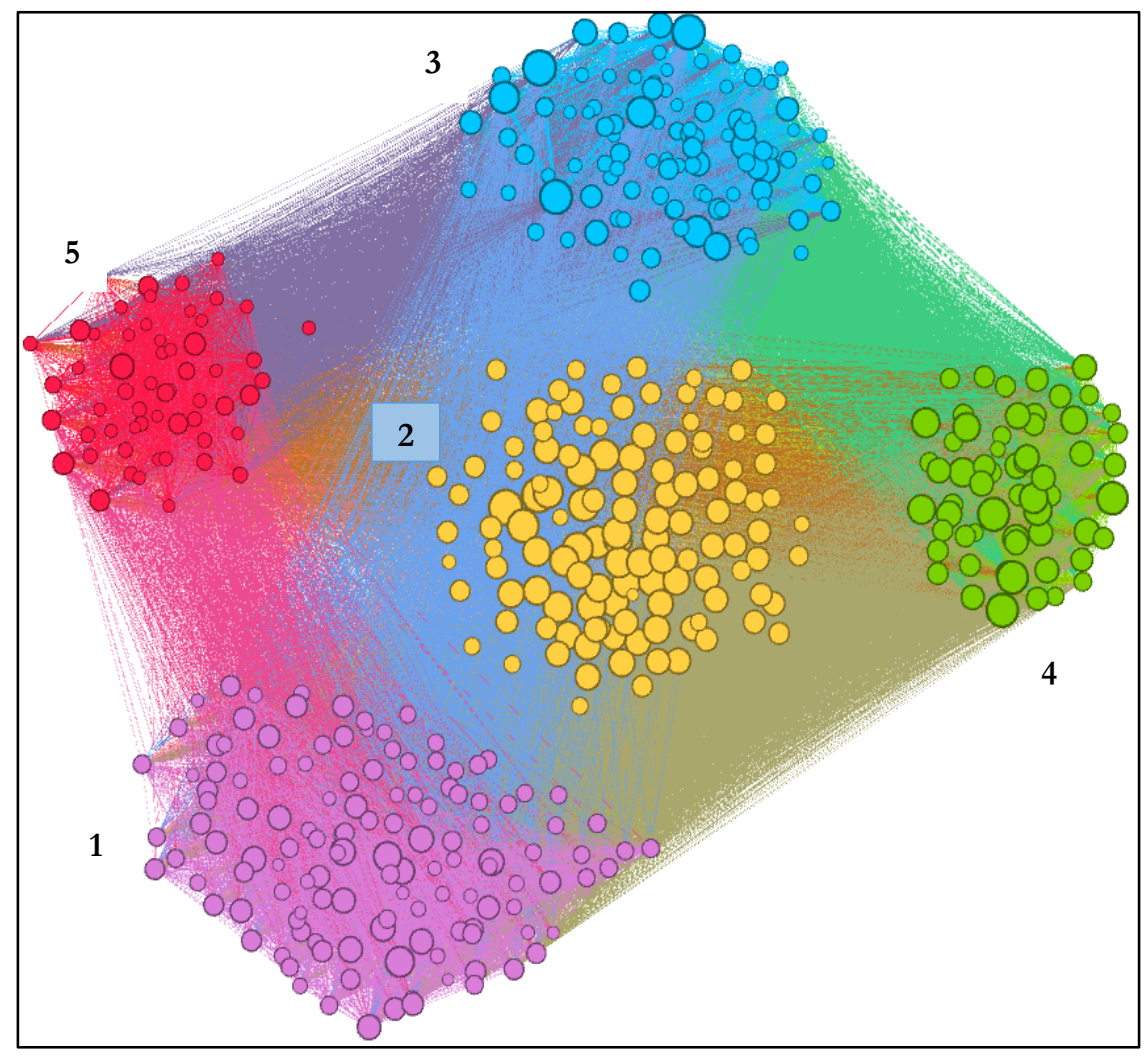

Figure 1. Structure of five clusters

Next, we found that studies in Cluster 2 are focussed on different perspectives on supply chain risk management. These studies proposed frameworks to identify and mitigate supply chain risks and improve performance, and even considered empirical cases to illustrate the application of these frameworks. With a focus on minimizing supply chain risks and disruptions, the research area in Cluster 3 overlaps with that of Cluster 2. However, the difference between the two is that researchers in Cluster 3 also focused on managing and mitigating disruption risks in the supply chain, making decisions on single or dual sourcing during disruption and its impact on supply chain performance. Although cluster 4 overlaps with cluster 3 in a sense that both are focussed on risk mitigation strategies, works in cluster 4 mainly emphasize on understanding and building resilient supply chains to deal with catastrophic events. Finally, researchers in Cluster 5 were mainly interested in developing various contracts, such as, revenue-sharing, option, and quantity-flexibility contracts, in order to avoid uncertainty and maintain supply chain coordination. Thus, it can be seen that the last two clusters are majorly focussed on identifying the causes and mitigating the impacts of the ripple effect developed in the supply chain.

Table 2. Top 10 publications of each cluster

\begin{tabular}{|l|l|}
\hline Cluster $\mathbf{1}$ & Cluster $\mathbf{2}$ \\
\hline Lee Hau L., 2004 & Tang C.S., 2006 \\
\hline
\end{tabular}




\begin{tabular}{|c|c|}
\hline $\begin{array}{l}\text { Lee, Hau L., Padmanabhan, V. and Whang, S., } \\
1997\end{array}$ & Chopra S. and Sodhi, M.S., 2004 \\
\hline Kraljic P., 1983 & Norrman A. and Jansson, U., 2004 \\
\hline Fornell C. and Larcker D.F., 1981 & $\begin{array}{l}\text { Sodhi M.S., Son, B.G. and Tang C.S., } \\
2012\end{array}$ \\
\hline Lee Hau L., 2002 & Tang C., and Tomlin, B., 2008 \\
\hline Fisher M. L., 1997 & $\begin{array}{l}\text { Juttner U., Peck, H. and Christopher } \\
\text { M., } 2003\end{array}$ \\
\hline Chen I. J. and Paulraj A., 2004 & Christopher M. and Lee, H., 2004 \\
\hline Eisenhardt K. M., 1989 & Tang O., 2011 \\
\hline Seuring S., and Müller M., 2008 & Wagner S.M. and Bode, C., 2008 \\
\hline $\begin{array}{l}\text { Podsakoff P.M., MacKenzie S.B., Lee, J.Y. and } \\
\text { Podsakoff, N.P., } 2003\end{array}$ & $\begin{array}{l}\text { Zsidisin G. A., Ellram L.M., Carter, J.R. } \\
\text { and Cavinato, J.L., } 2004\end{array}$ \\
\hline Cluster 3 & Cluster 4 \\
\hline Kleindorfer P.R. and Saad, G.H., 2005 & $\begin{array}{l}\text { Craighead C.W., Blackhurst, J., } \\
\text { Rungtusanatham, M.J. and Handfield, } \\
\text { R.B., } 2007\end{array}$ \\
\hline Tomlin B., 2006 & Christopher M. and Peck, H., 2004 \\
\hline $\begin{array}{l}\text { Hendricks K.B., Hendricks, Kevin B., and Singhal, } \\
\text { V.R., } 2005\end{array}$ & Tang C., 2006 \\
\hline Hendricks K.B. and Singhal, V.R., 2003 & Sheffi Y. and James B. Rice Jr, 2005 \\
\hline Hendricks K.B. and Singhal, V.R., 2005 & Sheffi Y., 2001 \\
\hline Sheffi Y., 2005 & $\begin{array}{l}\text { Blackhurst J., Craighead C.W., Elkins, } \\
\text { D. and Handfield, R.B., } 2005\end{array}$ \\
\hline Yu, Haisheng, Zeng, A.Z. and Zhao, L., 2009, & $\begin{array}{l}\text { Knemeyer A.M., Zinn, W. and Eroglu, } \\
\text { C., } 2009\end{array}$ \\
\hline Wilson MC, 2007 & $\begin{array}{l}\text { Ponomarov S. Y. and Holcomb, M.C., } \\
2009\end{array}$ \\
\hline Chopra S., Reinhardt, G. and Mohan U., 2007 & $\begin{array}{l}\text { Braunscheidel M. J. and Suresh, N.C., } \\
2009\end{array}$ \\
\hline Sawik T., 2013 & Ivanov D., 2014 \\
\hline \multicolumn{2}{|l|}{ Cluster 5} \\
\hline \multicolumn{2}{|l|}{ Cachon G.P., 2004} \\
\hline \multicolumn{2}{|l|}{ Cachon G.P, Lariviere, M.A., 2005} \\
\hline \multicolumn{2}{|l|}{ Kahneman D., 1979} \\
\hline \multicolumn{2}{|l|}{ Li C.L. and Kouvelis, P., 1999} \\
\hline \multicolumn{2}{|l|}{ Huchzermeier A. and Cohen, M.A., 1996} \\
\hline \multicolumn{2}{|l|}{ Tsay A.A., 1999} \\
\hline \multicolumn{2}{|l|}{ Agrawal V. and Seshadri S., 2000} \\
\hline \multicolumn{2}{|l|}{ Tsay A. A. and Lovejoy, W.S., 1999} \\
\hline \multicolumn{2}{|l|}{ Markowitz H., 1952} \\
\hline Gan Xianghua, Sethi S.P. and Yan H., 2005 & \\
\hline
\end{tabular}

\subsection{Meta-analysis}


Some researchers consider meta-analysis as an appropriate alternative for descriptive review and qualitative analysis (Rosenthal, 1991). It is defined as a method to statistically synthesise existing literature to visualise the research background by combining and assessing the quantitative results of a large number of empirical studies (Batista et al., 2018; Fang and Zhang, 2018; Glass, 1976; Soheilirad et al., 2018). More precisely, it enables results from multiple studies (Glass, 1976; Rana et al., 2015) to be accumulated for the estimates of true effect-sizes of relationships (Dwivedi et al., 2017). Previous research studies have shown meta-analysis as a valuable tool for research synthesis (Dwivedi et al., 2017; Wu and Lederer, 2009). The widespread use of meta-analysis affirms to its growing reputation as a tool for strengthening the prior knowledge and annotating mixed findings (Fang and Zhang, 2018). Table 3 presents the summary of zero-order correlations between a range of different pair of constructs from 29 empirical studies on SCRM. The metaanalysis found 24 such correlations between a pair of variables that occurred two or more times. The results revealed that the effect sizes for 18 out of 24 correlations were found significant at $\mathrm{p}<0.05, \mathrm{p}<0.01$ and $\mathrm{p}<0.001$ levels whereas the effect sizes for remaining seven correlations were found non-significant (i.e. $\mathrm{p}>0.05$ ). In addition to present a pair of variables between which the correlations were analysed two or more times, the table also presents the number of times a particular correlation was examined, total sample size (TSS) for all the studies where a specific pair of correlations were examined, average (r), significance of effect size (i.e. $\mathrm{p}(\mathrm{ES})$ ), standard normal deviations $(Z)$ and 95\% lower and upper confidence interval that support the correlation value likely to fall in this interval. The correlations between SUI-CUI $(r=0.463)$, INI-CUI $(r=0.422)$, SIS-PER ( $\mathrm{r}=0.488)$ and INR-CSR $(\mathrm{r}=0.396)$ are particularly strong. However, the correlations between BSR-PER ( $r=-0.094)$, DER-PER ( $r=-0.121)$, DER-CSR ( $r=0.130)$, INI-PER $(r=-0.110)$, DER-CUI ( $\mathrm{r}=-0.236)$, DER-INR ( $\mathrm{r}=0.205)$, BSR-RMA $(\mathrm{r}=0.120)$ and INR-FIR $(\mathrm{r}=0.210)$ are significant but their average(r) is relatively less strong. The $95 \%$ confidence interval for the correlations between DER-BSR, BSR-PER, DER-PER, DER-CSR, BSR-CSR, DER-INR and BSR-RMA indicates their range difference (i.e. $95 \% \mathrm{H}(\mathrm{r})-95 \% \mathrm{~L}(\mathrm{r})$ ) of less than two, which reveals that the range is narrow enough to provide one's confidence to the level of variance that could be explained and in the majority of the cases that the sample is large enough to approximate such parameters. Although correlations between different variables have been largely found as strong and relatively less strong but significant correlations, it can be argued that most of these meta-analytic correlations (except for first two in Table 3) are still in its infancy stage and needs more studies to establish their consistent and more stable representation of these values.

Table 3. Summary of Zero-Order Random Correlations

\begin{tabular}{|l|l|l|l|l|l|l|l|l|}
\hline IV & DV & $\#$ & TSS & Avg $(r)$ & p(ES) & Z-value & $95 \% \mathrm{~L}(\mathrm{r})$ & $95 \% \mathrm{H}(\mathrm{r})$ \\
\hline
\end{tabular}




\begin{tabular}{|c|c|c|c|c|c|c|c|c|} 
DER & BSR & 6 & 2317 & 0.341 & 0.000 & 7.403 & -0.255 & -0.421 \\
\hline BSR & PER & 4 & 1396 & -0.094 & 0.001 & -3.179 & -0.151 & -0.036 \\
\hline DER & PER & 3 & 1212 & -0.121 & 0.000 & -4.210 & -0.176 & -0.065 \\
\hline SUI & CUI & 3 & 1172 & 0.463 & 0.000 & 6.199 & 0.330 & 0.578 \\
\hline DER & CSR & 2 & 1520 & 0.130 & 0.000 & 5.087 & 0.080 & 0.179 \\
\hline BSR & CSR & 2 & 1520 & 0.310 & 0.000 & 12.472 & 0.264 & 0.355 \\
\hline INI & CUI & 2 & 535 & 0.422 & 0.000 & 9.068 & 0.339 & 0.499 \\
\hline RLB & CSR & 2 & 864 & 0.381 & 0.000 & 5.000 & 0.239 & 0.507 \\
\hline INI & PER & 2 & 1009 & -0.110 & 0.000 & -3.493 & -0.170 & -0.048 \\
\hline SIS & PER & 2 & 581 & 0.488 & 0.000 & 4.523 & 0.293 & 0.643 \\
\hline INR & CSR & 2 & 864 & 0.396 & 0.002 & 3.098 & 0.153 & 0.594 \\
\hline BSR & SUI & 2 & 520 & -0.343 & 0.006 & -2.750 & -0.545 & -0.102 \\
\hline POR & PER & 2 & 452 & -0.203 & 0.191 & -1.308 & -0.474 & -0.102 \\
\hline DER & CUI & 2 & 520 & -0.236 & 0.000 & -5.445 & -0.315 & -0.153 \\
\hline DER & INR & 2 & 1009 & 0.205 & 0.000 & 6.583 & 0.145 & 0.263 \\
\hline DER & RMA & 2 & 1009 & -0.042 & 0.180 & -1.340 & -0.104 & -0.020 \\
\hline BSR & INR & 2 & 1009 & 0.294 & 0.001 & 3.274 & 0.121 & 0.450 \\
\hline BSR & RMA & 2 & 1009 & 0.120 & 0.000 & 3.819 & 0.059 & 0.180 \\
\hline INR & RMA & 2 & 1009 & 0.000 & 0.997 & -0.004 & -0.136 & 0.135 \\
\hline PER & RMA & 2 & 1009 & 0.110 & 0.115 & 1.575 & -0.027 & 0.243 \\
\hline OPR & INR & 2 & 353 & 0.206 & 0.566 & 0.573 & -0.465 & 0.727 \\
\hline OPR & RMA & 2 & 341 & 0.188 & 0.096 & 1.664 & -0.034 & 0.391 \\
\hline OPR & FIR & 2 & 353 & -0.009 & 0.964 & -0.045 & -0.366 & 0.350 \\
\hline INR & FIR & 2 & 353 & 0.210 & 0.043 & 2.019 & 0.006 & 0.398 \\
\hline
\end{tabular}

[Note: BSR: Supply side Risk, CSR: Catastrophic Risk, CUI: Customer Integration, DER: Demand Side Risk, DV: Dependent Variable, IV: Independent Variable, FIR: Financial Risk, H(r): Higher (r), INI: Internal Integration, INR: Logistics and Infrastructure Risk, L(r): Lower (r), PER: Operational Performance, POR: Political Risk, RMA: Risk Management, OPR: Operational Risk, SIS: Supply Chain Risk Information Sharing, SUI: Supplier Integration, TSS: Total Sample Size]

\section{Discussion and Analysis}

Through this article focusing on 42 years of SCRM, we realized that this field has evolved significantly over these past few decades. A large number of studies have focused on identification of risk, assessments, mitigation and monitoring (Christopher and Peck, 2004; Chopra and Sodhi, 2004; Wagner and Bode, 2008). In this regard, authors have developed various frameworks and proposed mitigation strategies in order to minimize the impact of supply chain risks and disruptions on performance. In addition, we noted a recent interest of authors (Ivanov, 2017a, b; Ivanov, 2018; He et al., 2018) towards the concept of ripple effect in supply chains. By defining ripple effect as the impact of a disruption propagation on supply chain performance, they identified the reasons and mitigation strategies to deal with the ripple effect in supply chains and proposed ripple effect control framework focusing on redundancy, flexibility and resilience.

Based on our network analysis, we have proposed five clusters that focus on conceptualization of supply chain management, followed by SCRM, risk management tools and techniques, effects of 
risk/disruptions and supply chain coordination. We noticed that there are significant number of studies on the first three clusters whereas, there are comparatively fewer studies emphasizing the negative impact of risk/disruptions on supply chain and building supply chain coordination. This indicates that there is a scope of future research on these two clusters and it appears that researchers have already started working on similar lines as the concept of ripple effect in supply chains has gained significant attention recently.

Further, the findings of meta-analysis indicate that variables used in this research and their interrelationships are very scattered in nature and majority of them have been empirically examined only a very few times in the context of SCRM. This is evident from the fact that out of 24 correlations between 13 different variables only four have been examined three or more times. Therefore, no firm conclusions can be drawn from 20 interrelationships that have been empirically examined only two times with either significant or non-significant meta-analytic outcomes. Some non-significant outcomes also indicate that their overall sample size is relatively small and hence may not be the right representatives of their outcomes and could be a cause of concern. The outcomes for variables examined three or more times indicate that on the one hand higher degree of demand side risk would lead to higher level of supply side risk, but on the other hand both these risks adversely influence the organizational operational performance (Wagner and Bode, 2008). Moreover, supply integration was found to have a positively correlated with customer integration. As the customer integration involves identifying customer requirements and modifying internal activities to meet these requirements, we argue that this could be possible only with supplier integration, which provides a firm an opportunity to focus on its core competencies and particular areas of expertise (He et al., 2014).

\subsection{Contributions to theory and implications for practice}

The contribution of this paper is to provide an overview of research published in various journals about SCRM. It extends existing reviews in that it goes beyond a mere systematic, bibliometric or network analysis based literature review of the field since it not only utilizes the technique of network analysis but also conducts meta-analysis of empirical studies to understand the relationship between various constructs of the studies. Our network analysis identifies five research clusters that focus on various areas of SCRM, ranging from conceptual studies utilizing theories to investigating the effect of supply chain disruption on organizational performance. It also depicts step-by-step development of the SCRM area of research through these clusters, and suggests that researchers should focus on Clusters 4 and 5 and investigate the effect of supply 
chain risk or ripple effect on its performance. Using meta-analysis, the researchers can gain confidence about the type of variables to be selected for analyzing a range of constructs in SCRM. The under-represented and frequently used variables along with their overall effect sizes (i.e. average (r)) and significance can guide the researchers to make a careful decision about the appropriate selection of variables (Rana et al., 2015). As none of the existing studies have undertaken meta-analysis of variables in the SCRM domain, our research contributes not only in recognizing some of the repeating variables but also analyzes their overall performance. The metaanalyses of eight correlations including POR-PER, DER-RMA, INR-RMA, PER-RMA, OPRINR, OPR-RMA, OPR-FIR and INR-FIR indicate that their overall effect-sizes are nonsignificant, which informs the future researchers that they should be considered with caution (Fan et al., 2017). Moreover, it is difficult to provide a firm conclusion of non-significance of average correlations based on the meta-analysis of only limited occurrence between a pair of variables. More precisely, all non-significant correlation values are based on only two individual values and hence more studies on these variables would be needed to get to the firm conclusion about the stability of synthesized values. They should also work towards minimizing the supply and demand side risk in the organization to ensure better supplier integration and optimizing logistics and infrastructure risk. Thus, this study can assist researchers in understanding the current state of SCRM, and in developing an appreciation of this research area and different issues considered worthy of research and publication.

We offer multiple opportunities and schools of thought to managers who are involved in harnessing the benefits of mitigation strategies for minimizing supply chain risks in their everyday work. The five-cluster classification presented in this paper provides a tool for managers to assess the current state of SCRM in terms of conceptualisation and risk mitigation strategies and identify their future needs in the relevant clusters so that they may decide whether to invest and improve current tools/techniques in order to minimize supply chain risk, and thus enhance their firm performance through SCRM. The meta-analysis results for supply side and demand side risks indicate that they negatively influence operational performance of the companies. This signifies that the managers should minimize these value chain risks to optimize the organizational performance. Moreover, the strong and significant effect size between supply integration and customer integration indicates that managers should maintain a close collaboration with suppliers, access to an integrated information system spanning multiple functions and logical integration between suppliers and customers into a joint supply chain. The managers should also share 
information related to supply chain risk with other members of organization so that a proper measure could be taken on time to improve its operational performance.

\subsection{Future research directions}

Adopting network and meta-analysis techniques, our study generated the following future directions that can help new researchers to establish their research agenda in this field. First, our network analysis reveals that studies in SCRM are often not based on consolidated theories, rather employs a single theory at a time. This points to a significant gap in the literature as the findings based on theoretically grounded and replicated work are more robust and can be generalized easily. Thus, future studies may first adopt and replicate commonly used theories like Contingency Theory, Theory of Constraints, Resource Based View, Theory of Complementarity, SocioTechnical System theory and Organizational Theory. Second, we suggest adopting theories like Actor Network Theory, Agency Theory and Systems Theory that are used only one time. We believe that through the inclusion of these theoretical perspectives in our thinking, it will be easy to understand the latest trends in SCRM because they emphasize on both organizational and technical dimensions and their relationships, thereby explaining how different risk mitigation strategies can be adapted and adopted in varied contexts. Our review also reveals that there is a need to conduct further studies to understand the impact of supply chain risks on organizational performance. Another direction for future studies is related to the country in which the research is done. Our meta-analysis reflects that data is often collected from a single country without considering the effect of national culture, and thus a cross-country data collection approach could be adopted in future works. Besides, the scope of this review can be further enhanced by including additional keywords in the literature search, using alternative databases, or analysing the grey literature. The proposed five cluster classification depicting different clusters, current research and suggestions for future research for each of the clusters are summarized in Table 4.

Table 4. Proposed cluster classification with current and future research per cluster

\begin{tabular}{|l|l|l|}
\hline Cluster number and label & Current research & Future research suggestions \\
\hline Cluster 1 & $\begin{array}{l}\text { Theoretical and conceptual } \\
\text { studies on supply chain } \\
\text { Sanply chain } \\
\text { management }\end{array}$ & $\begin{array}{l}\text { Future studies may first adopt and } \\
\text { replicate commonly used theories } \\
\text { like Contingency Theory, Theory } \\
\text { of Constraints, Resource Based } \\
\text { View and Organizational Theory } \\
\text { and understand the trends in } \\
\text { SCRM }\end{array}$ \\
\hline Cluster 2 & \\
\hline
\end{tabular}




\begin{tabular}{|c|c|c|}
\hline $\begin{array}{l}\text { Supply chain risk } \\
\text { management }\end{array}$ & $\begin{array}{l}\text { - Supply chain risk typologies } \\
\text { have been proposed } \\
\text { - Few empirical studies } \\
\text { conducted with the aim to } \\
\text { minimize supply chain risk } \\
\text { - Conceptual frameworks on } \\
\text { risk identification, } \\
\text { assessment, mitigation and } \\
\text { monitoring have been } \\
\text { developed }\end{array}$ & $\begin{array}{l}\text { - Detailed analysis on SCRM } \\
\text { - Develop frameworks for SCRM } \\
\text { using organizational theories } \\
\text { Frameworks on risk recovery } \\
\text { should be studied so that supply } \\
\text { chain can easily recover after the } \\
\text { occurrence of a disruption }\end{array}$ \\
\hline \multicolumn{3}{|l|}{ Cluster 3} \\
\hline $\begin{array}{l}\text { Risk management tools } \\
\text { and techniques }\end{array}$ & $\begin{array}{l}\text { - Conceptual frameworks } \\
\text { related to SCRM } \\
\text { management methods and } \\
\text { mitigating strategies have } \\
\text { been developed } \\
\text { - Effects of minimizing supply } \\
\text { chain risk on performance }\end{array}$ & $\begin{array}{l}\text { - Empirically validate the } \\
\text { frameworks on SCRM using } \\
\text { single and/or multiple country } \\
\text { data } \\
\text { - Improve supply chain } \\
\text { performance and efficiency using } \\
\text { mitigation strategies }\end{array}$ \\
\hline \multicolumn{3}{|l|}{ Cluster 4} \\
\hline $\begin{array}{l}\text { Investigate the effects of } \\
\text { risk/disruptions }\end{array}$ & $\begin{array}{l}\text { - Supply chain complexity } \\
\text { - Methodologies for dealing } \\
\text { with ripple effects } \\
\text { - Studied different set of } \\
\text { factors that give rise to } \\
\text { disruptions } \\
\text { - Effect of Supply Chain } \\
\text { Disruptions on long-run } \\
\text { Stock Price Performance and } \\
\text { stakeholder's wealth }\end{array}$ & $\begin{array}{l}\text { - Robust and advanced tools and } \\
\text { techniques for SCRM } \\
\text { - Advanced IT based methods } \\
\text { should be incorporated in ripple } \\
\text { effect scenario } \\
\text { - Practical implication of simulation } \\
\text { and optimization risk mitigating } \\
\text { methods } \\
\text { Develop } \\
\text { measurement system for } \\
\text { analyzing ripple effect impact } \\
\text { Investigate the correlations } \\
\text { between risk factors and } \\
\text { corresponding risk types } \\
\text { Case studies and frameworks to } \\
\text { improve performance and wealth }\end{array}$ \\
\hline \multicolumn{3}{|l|}{ Cluster 5} \\
\hline $\begin{array}{l}\text { Building supply chain } \\
\text { coordination }\end{array}$ & $\begin{array}{l}\text { - Coordination through } \\
\text { revenue sharing, option and } \\
\text { quantity flexibility contract } \\
\text { - Methods to minimize supply } \\
\text { chain uncertainty }\end{array}$ & $\begin{array}{l}\text { - Advanced tools and techniques } \\
\text { for proactive planning to deal } \\
\text { with ripple effect } \\
\text { - Empirical-Simulation based } \\
\text { studies should be conducted for } \\
\text { minimizing the ripple effect in } \\
\text { supply chain } \\
\text { - Sustainability and humanitarian } \\
\text { aspects related to disruptions } \\
\text { should be explored }\end{array}$ \\
\hline
\end{tabular}

\section{Conclusions}


This study is a review of SCRM literature that identifies, and analyses 2,564 articles published from 1976 to December, 2018 in peer-reviewed scientific journals. Given the recent growth, we aimed at providing an updated picture of the current state of SCRM research and identifying trajectories for future studies. With this aim, we first performed network analysis and identified five emerging research clusters, and then offered meta-analysis of empirical studies in order to ascertain the relationship between major constructs of the study. To the best of our knowledge, this is the first study that employs the above-mentioned techniques to include both conceptual and empirical articles focusing on all the aspects of SCRM including ripple effect.

Although we conducted a comprehensive analysis of SCRM literature, our research has few limitations. One of the main limitations is restricting the criteria of keywords with the filter that this term had to be in the paper title, abstract and keywords, eventually, relevant papers may have been excluded. While the review article was guided by an established review methodology, the methodology used could limit the results as it focused only on articles that were written in English and appeared in WoS database. Further, we considered articles and reviews published in peerreviewed academic journals and did not include unpublished works, book chapters and conferences. These decisions could lead to exclude relevant studies and limit creativity and innovations. In addition, majority of meta-analyses between constructs are based on two correlations only. The future research could consider some more empirical studies to increase the number of correlations being examined for meta-analysis. Despite these limitations, we believe that our study provides food for thought and encouragement for researchers to further investigate the field of SCRM.

\section{References}

Aloulou M.A., Dolgui A., and Kovalyov M.Y. 2014. "A bibliography of non-deterministic lotsizing models". International Journal of Production Research 52(8), 2293-2310.

Anderson, E. and Oliver, R.L. 1987. "Perspectives on behavior-based versus outcome-based salesforce control systems". The Journal of Marketing 76-88.

Aven, T. 2017. "How some types of risk assessments can support resilience analysis and management". Reliability Engineering and System Safety 167, 536-543.

Azaron, A., K. N. Brown, S. A. Tarim, and M. Modarres. 2008. "A Multi-objective Stochastic Programming Approach for Supply Chain Design Considering Risk." International Journal of Production Economics 116 (1): 129-138.

Batista, L., Bourlakis, M., Smart, P., and Maull, R. 2018. "In search of a circular supply chain archetype-a content-analysis-based literature review". Production Planning \& Control, 29(6): 438-451. 
Blondel, VD, Guillaume, JL, Lambiotte, R, Lefebvre, E. Fast unfolding of communities in large networks. J. Stat. Mech.: Theory Exp. 2008, P10008Clauset, A., Newman, M.E.J., Moore, C., 2004. Finding community structure in very large networks. Phys. Rev. E 70,1-6.

Bode, C., Wagner, S.M., Petersen, K.J. and Ellram, L.M. 2011. "Understanding responses to supply chain disruptions: Insights from information processing and resource dependence perspectives". Academy of Management Journal 54(4): 833-856.

Carvalho, H., A. P. Barroso, V. H. Machado, S. Azevedo, and V. Cruz-Machado. 2012. "Supply Chain Redesign for Resilience Using Simulation.” Computers \& Industrial Engineering 62 (1): 329_ 341.

Chen, Q., X. Li, and Y. Ouyang. 2011. "Joint Inventory-location Problem under the Risk of Probabilistic Facility Disruptions.” Transportation Research Part B: Methodological 45 (7): 991-1003.

Choi, T.Y. and Liker, J.K. 1995. "Bringing Japanese continuous improvement approaches to US manufacturing: the roles of process orientation and communications". Decision Sciences 26(5): 589620.

Chopra, S. and Sodhi, M.S. 2004. "Managing risk to avoid supply-chain breakdown". MIT Sloan Management Review 46(1): 53.

Christopher, M. and Peck, H. 2004. "Building the resilient supply chain". The International Journal of Logistics Management 15(2): 1-14.

Christopher, M. and Towill, D.R. 2002. "Developing market specific supply chain strategies". The International Journal of Logistics Management 13(1): 1-14

Colicchia, C. and Strozzi, F. 2012. "Supply chain risk management: a new methodology for a systematic literature review". Supply Chain Management: An International Journal 17(4): 403-418.

Cousins, P.D., Lamming, R.C. and Bowen, F. 2004. "The role of risk in environment-related supplier initiatives". International Journal of Operations \& Production Management 24(6): 554-565.

Dolgui A., and Prodhon C. 2007. "Supply planning under uncertainties in MRP environments: a state of the art". Annual Reviews in Control 31, 269-279.

Dolgui A., Ben Ammar O., Hnaien F., and Louly M.-A. 2013. "A state of the art on supply planning and inventory control under lead time uncertainty". Studies in Informatics and Control 22(3), 255-268.

Dolgui, A., Ivanov, D., \& Sokolov, B. 2018. "Ripple effect in the supply chain: an analysis and recent literature". International Journal of Production Research, 56(1-2): 414-430.

Dolgui, A., Ivanov, D. and Rozhkov, M., 2019. "Does the ripple effect influence the bullwhip effect? An integrated analysis of structural and operational dynamics in the supply chain”. International Journal of Production Research, 1-17.

Dwivedi, Y. K., Rana, N. P., Jeyaraj, A., Clement, M., and Williams, M. D. 2017. "Re-examining the Unified Theory of Acceptance and Use of Technology (UTAUT): Towards a Revised 
Theoretical Model". Information Systems Frontiers 1-16. DoI: https://doi.org/10.1007/s10796-0179774-y.

Fahimnia, B., Tang, C.S., Davarzani, H. and Sarkis, J. 2015. "Quantitative models for managing supply chain risks: A review”. European Journal of Operational Research 247(1): 1-15.

Fan, H., Li, G., Sun, H., and Cheng, T. C. E. 2017. “An information processing perspective on supply chain risk management: Antecedents, mechanism, and consequences". International Journal of Production Economics 185: 63-75.

Fang, C., \& Zhang, J. 2018. "Performance of green supply chain management: A systematic review and meta analysis". Journal of Cleaner Production, 183: 1064-1081.

Garvey, M.D., Carnovale, S. and Yeniyurt, S. 2015. "An analytical framework for supply network risk propagation: A Bayesian network approach". European Journal of Operational Research 243(2): 618-627.

Gephi. (2013). Gephi-Makes graphs handy. https://gephi.org.

Glass, G. V. 1976. "Primary, secondary, and meta-analysis of research". Educational researcher $5(10): 3-8$.

Goh, M., J. Y. S. Lim, and F. Meng. 2007. "A Stochastic Model for Risk Management in Global Supply Chain Networks.” European Journal of Operational Research 182 (1): 164-173.

Hallikas, J., Karvonen, I., Pulkkinen, U., Virolainen, V.M. and Tuominen, M. 2004. "Risk management processes in supplier networks". International Journal of Production Economics 90(1):4758.

Han J., and Shin K.S. 2016. "Evaluation mechanism for structural robustness of supply chain considering disruption propagation”. International Journal of Production Research 54(1), 135-151.

Hasani, A., and A. Khosrojerdi. 2016. "Robust Global Supply Chain Network Design under Disruption and Uncertainty Considering Resilience Strategies: A Parallel Memetic Algorithm for a Real-life Case Study." Transportation Research Part E: Logistics and Transportation Review 87: 20-52.

He, Y., Lai, K.K. Sun, H. and Chen, Y. 2014. "The impact of supplier integration on customer integration and new product performance: The mediating role of manufacturing flexibility under trust theory". International Journal of Production Economics 147:260-270.

He, J., Alavifard, F., Ivanov, D. and Jahani, H., 2018. "A real-option approach to mitigate disruption risk in the supply chain." Omega: The International Journal of Management Science, in press.

Heckmann, I., Comes, T. and Nickel, S. 2015. "A critical review on supply chain risk-Definition, measure and modelling”. Omega, 52: 119-132.

Hendricks, K.B. and Singhal, V.R. 2005. "An empirical analysis of the effect of supply chain disruptions on long-run stock price performance and equity risk of the firm". Production and Operations management 14(1): 35-52. 
Ho, W., Zheng, T., Yildiz, H. and Talluri, S. 2015. "Supply chain risk management: a literature review". International Journal of Production Research 53(16): 5031-5069.

Hosseini, S., Ivanov, D. and Dolgui, A., 2019. "Review of quantitative methods for supply chain resilience analysis". Transportation Research Part E: Logistics and Transportation Review, 125, 285-307.

Ismagilova, E., Slade, E. L., Rana, N. P., and Dwivedi, Y. K. 2019. “The Effect of Electronic Word of Mouth Communications on Intention to Buy: A Meta-Analysis". Information Systems Frontiers, 1-24, DoI: 10.1007/s10796-019-09924-y.

Ivanov, D., 2019. "Disruption tails and revival policies: A simulation analysis of supply chain design and production-ordering systems in the recovery and post-disruption periods". Computers \& Industrial Engineering, 127, 558-570.

Ivanov, D. and Sokolov, B., 2019. "Simultaneous structural-operational control of supply chain dynamics and resilience". Annals of Operations Research, 1-20.

Ivanov, D., Dolgui, A., and Sokolov, B. 2019a. "The impact of digital technology and Industry 4.0 on the ripple effect and supply chain risk analytics". International Journal of Production Research, 57(3), 829-846.

Ivanov, D., Dolgui, A. and Sokolov, B., 2019b. "Ripple Effect in the Supply Chain: Definitions, Frameworks and Future Research Perspectives". In Handbook of Ripple Effects in the Supply Chain (pp. 1-33). Springer, Cham.

Ivanov D. 2018a. Structural dynamics and resilience in supply chain risk management. Springer International Publishing.

Ivanov, D., 2018b. "Revealing interfaces of supply chain resilience and sustainability: a simulation study”. International Journal of Production Research, 56(10), 3507-3523.

Ivanov, D. 2018c. Uncertainty and Risks (Chapter 2). Structural Dynamics and Resilience in Supply Chain Risk Management (Eds. Ivanov, D), pp. 19-44. Springer International Publishing: London.

Ivanov, D., and Dolgui, A. 2018. "Low-Certainty-Need (LCN) supply chains: a new perspective in managing disruption risks and resilience". International Journal of Production Research,1-18.

Ivanov, D., Dolgui, A., and Sokolov, B. (2018). Scheduling of recovery actions in the supply chain with resilience analysis considerations. International Journal of Production Research, 56(19): 6473-6490.

Ivanov, D. 2017a. "Simulation-based Ripple Effect Modelling in the Supply Chain." International Journal of Production Research 55 (7): 1083-1101.

Ivanov, D. 2017b. "Simulation-based Single vs. Dual Sourcing Analysis in the Supply Chain with Consideration of Capacity Disruptions, Big Data and Demand Patterns." International Journal of Integrated Supply Management 11 (1): 24-43. 
Ivanov, D., A. Tsipoulanidis, and J. Schönberger. 2017. Global Supply Chain and Operations Management. 1st ed. London: Springer International.

Ivanov, D., Dolgui A., Sokolov B., and Ivanova M. 2017a. "Literature review on disruption recovery in the supply chain". International Journal of Production Research 55(20), 6158-6174.

Ivanov, D., Dolgui, A., Sokolov, B., and Ivanova, M. 2017b. "Literature review on disruption recovery in the supply chain". International Journal of Production Research 55(20): 6158-6174.

Ivanov D., Pavlov A., Pavlov D., and Sokolov B. 2017. "Minimization of disruption-related return flows in the supply chain”. International Journal of Production Economics 183, 503-513.

Ivanov, D., B. Sokolov, A. Pavlov, A. Dolgui, and D. Pavlov. 2016. "Disruption-Driven Supply Chain (Re)-planning and Performance Impact Assessment with Consideration of pro-Active and Recovery Policies." Transportation Research Part E: Logistics and Transportation Review 90: 7-24.

Ivanov, D., B. Sokolov, A. Dolgui, I. Solovyeva, and F. Jie. 2016a. "Dynamic Recovery Policies for Time-critical Supply Chains under Conditions of Ripple Effect." International Journal of Production Research 54 (11): 3397-3413.

Ivanov, D., B. Sokolov, A. Dolgui, I. Solovyeva, and F. Jie. 2016b. "Dynamic Recovery Policies for Time-critical Supply Chains under Conditions of Ripple Effect." International Journal of Production Research 54 (11): 3397-3413.

Ivanov, D., Sokolov, B. and Dolgui, A. 2014. "The Ripple effect in supply chains: trade-off 'efficiency-flexibility-resilience' in disruption management'. International Journal of Production Research 52(7): 2154-2172.

Ivanov, D., B. Sokolov, and A. Pavlov. 2014. "Optimal Distribution (Re)Planning in a Centralized Multi-stage Network under Conditions of Ripple Effect and Structure Dynamics." European Journal of Operational Research 237 (2): 758-770.

Ivanov, D., B. Sokolov, and A. Pavlov. 2013. "Dual Problem Formulation and its Application to Optimal Re-design of an Integrated Production-Distribution Network with Structure Dynamics and Ripple Effect Considerations." International Journal of Production Research 51 (18): 5386-5403.

Ivanov, D., and B. Sokolov. 2013. "Control and System-theoretic Identification of the Supply Chain Dynamics Domain for Planning, Analysis, and Adaptation of Performance under Uncertainty.” European Journal of Operational Research 224 (2): 313-323.

Juttner, U., Peck, H. and Christopher, M. 2003. "Supply Chain Risk Management: Outlining an Agenda for Future Research". International Journal of Logistics: Research and Applications 6(4):197-210.

Kleindorfer, P.R. and Saad, G.H. 2005. "Managing disruption risks in supply chains". Production and Operations Management 14(1): 53-68.

Klibi, W., A. Martel, and A. Guitouni. 2010. "The Design of Robust Value-creating Supply Chain Networks: A Critical Review.” European Journal of Operational Research 203 (2): 283-293 
Kilubi, I. 2016. "The strategies of supply chain risk management-a synthesis and classification". International Journal of Logistics Research and Applications 19(6): 604-629.

Knemeyer, A. M., W. Zinn, and C. Eroglu. 2009. "Proactive Planning for Catastrophic Events in Supply Chains." Journal of Operations Management 27 (2): 141-153.

Leydesdorff, L. Bibliometrics/citation networks. In: Barnett, G.A. (Ed.), Encyclopaedia of Social Networks. SAGE Publications, Inc., Thousand Oaks, CA. 2011.

Lim M., Daskin M. S., Bassamboo A., and Chopra S. 2010. "A facility reliability problem: Formulation, properties and algorithm". Naval Research Logistics, 57(1), 58-70.

Lim, M. K., A. Bassamboo, S. Chopra, and M. S. Daskin. 2013. "Facility Location Decisions with Random Disruptions and Imperfect Estimation." Manufacturing and Service Operations Management 15 (2): 239-249.

Lin, Y. and Zhou, L. 2011. "The Impacts of Product Design Changes on Supply Chain Risk: A Case Study”. International Journal of Physical Distribution and Logistics Management 41: 162-186.

Lavastre, O., Gunasekaran, A., and Spalanzani, A. 2014. "Effect of firm characteristics, supplier relationships and techniques used on supply chain risk management (SCRM): an empirical investigation on French industrial firms". International Journal of Production Research 52(11):33813403.

Lee, H. L. 2004. “The triple-A supply chain”. Harvard Business Review 82(10):102-113.

Macdonald, J. R., Zobel, C. W., Melnyk, S. A., and Griffis, S. E. 2018. "Supply chain risk and resilience: theory building through structured experiments and simulation". International Journal of Production Research 56(12): 1-19.

Manuj, I., Esper, T.L. and Stank, T.S. 2014. "Supply chain risk management approaches under different conditions of risk". Journal of Business Logistics 35(3):241-258.

Manuj, I. and Mentzer, J.T. 2008. "Global supply chain risk management strategies". International Journal of Physical Distribution \& Logistics Management 38(3):192-223.

March, J.G. and Shapira, Z. 1987. "Managerial perspectives on risk and risk taking”. Management Science 33(11):1404-1418.

Mishra, D., Gunasekaran, A., Papadopoulos, T., and Childe, S. J. 2016a. "Big Data and supply chain management: a review and bibliometric analysis". Annals of Operations Research, 1-24.

Mishra, D, Gunasekaran, A, Childe, S.J, Papadopoulos, T, Dubey, R. and Wamba, F.S. 2016b. "Vision, applications and future challenges of Internet of Things". Industrial Management \& Data Systems 116(7):1331-1355

Mullai, A. 2009. "Risk management system-a conceptual model”. In Supply Chain Risk. Springer, Boston, MA 83-101.

Narasimhan, Ram, and Srinivas Talluri, 2009. "Perspectives on risk management in supply chains". 
114-118.

Pavlov, A., Ivanov, D., Dolgui, A. and Sokolov, B., 2017. "Hybrid fuzzy-probabilistic approach to supply chain resilience assessment". IEEE Transactions on Engineering Management, 65(2), 303-315.

Pavlov, A., Ivanov, D., Pavlov, D. and Slinko, A., 2019. "Optimization of network redundancy and contingency planning in sustainable and resilient supply chain resource management under conditions of structural dynamics". Annals of Operations Research, 1-30.

Prakash, S., Prakash, S., Soni, G., Soni, G., Rathore, A.P.S. and Rathore, A.P.S. 2017. “A critical analysis of supply chain risk management content: a structured literature review". Journal of Advances in Management Research 14(1):69-90.

Qazi, A., Quigley, J., Dickson, A. and Ekici, Ş.Ö. 2017. "Exploring dependency based probabilistic supply chain risk measures for prioritising interdependent risks and strategies". European Journal of Operational Research 259(1): 189-204.

Radicchi, F, Castellano, C, Cecconi, F, Loreto, V. and Parisi, D. 2004. "Defining and identifying communities in networks". Proceedings of the National Academy of Sciences of the United States of America 101:2658-2663.

Rafiei, M., M. Mohammadi, and S. Torabi. 2013. "Reliable Multi Period Multi Product Supply Chain Design with Facility Disruption." Decision Science Letters 2 (2): 81-94.

Rezapour, S., R. Farahani, and M. Pourakbar. 2017. "Resilient Supply Chain Network Design under Competition: A Case Study." European Journal of Operational Research 259 (3): 1017-1035.

Ramos-Rodríguez, A.R. and Ruíz-Navarro, J. 2004. "Changes in the intellectual structure of strategic management research: A bibliometric study of the Strategic Management Journal, 19802000”. Strategic Management Journal 25(10): 981-1004.

Rana, N. P., Dwivedi, Y. K., and Williams, M. D. 2015. "A meta-analysis of existing research on citizen adoption of e-government". Information Systems Frontiers 17(3): 547-563.

Rangel, D. A., de Oliveira, T. K., and Leite, M. S. A. 2015. "Supply chain risk classification: discussion and proposal". International Journal of Production Research 53(22): 6868-6887.

Rao, S. and Goldsby, T.J. 2009. "Global supply chain risk management strategies". The International Journal of Logistics Management 20(1): 97-123.

Ravindran, A.R., Ufuk Bilsel, R., Wadhwa, V. and Yang, T. 2010. "Risk adjusted multicriteria supplier selection models with applications". International Journal of Production Research 48(2): 405424.

Sawik, T. 2013. "Integrated Selection of Suppliers and Scheduling of Customer Orders in the Presence of Supply Chain Disruption Risks." International Journal of Production Research 51 (23-24): 7006-7022.

Scheibe, K. P., and Blackhurst, J. 2018. "Supply chain disruption propagation: A systemic risk and normal accident theory perspective." International Journal of Production Research 56(1-2), 43-59. 
Schmitt, A. J., and M. Singh. 2012. "A Quantitative Analysis of Disruption Risk in a Multi-echelon Supply Chain." International Journal of Production Economics 139 (1): 23-32.

Snyder L.V., and Daskin M. S. (2005). "Reliability models for facility location: The expected failure cost case." Transportation Science 39, 400-416.

Snyder L V., Zümbuil A., Peng P., Ying R., Schmitt A. J., and Sinsoysal B. 2016. "OR/MS Models for Supply Chain Disruptions: A Review." IIE Transactions 48(2), 89-109.

Sodhi, M.S., Son, B.G. and Tang, C.S. 2012. "Researchers' perspectives on supply chain risk management". Production and Operations Management 21(1):1-13.

Soheilirad, S., Govindan, K., Mardani, A., Zavadskas, E. K., Nilashi, M., and Zakuan, N. 2018. "Application of data envelopment analysis models in supply chain management: A systematic review and meta-analysis”. Annals of Operations Research, 271(2): 915-969.

Sokolov, B., Ivanov, D., Dolgui, A. and Pavlov, A., 2016. "Structural quantification of the ripple effect in the supply chain". International Journal of Production Research, 54(1), 152-169.

Tang, O. and Musa, S.N. 2011. "Identifying risk issues and research advancements in supply chain risk management". International Journal of Production Economics 133(1):25-34.

Tang, C.S. 2006. "Perspectives in supply chain risk management". International Journal of Production Economics 103(2): 451-488.

Torabi, S. A., M. Baghersad, and S. A. Mansouri. 2015. "Resilient Supplier Selection and Order Allocation under Operational and Disruption Risks." Transportation Research Part E: Logistics and Transportation Review 79: 22-48.

Tsiakis, P., N. Shah, and C. C. Pantelides. 2001. "Design of Multi-echelon Supply Chain Networks under Demand Uncertainty." Industrial and Engineering Chemistry Research 40: 3585-3604.

Wagner, S.M. and Bode, C. 2008. "An empirical examination of supply chain performance along several dimensions of risk". Journal of Business Logistics 29(1):307-325.

Wilson, M. C. 2007. "The Impact of Transportation Disruptions on Supply Chain Performance." Transportation Research Part E: Logistics and Transportation Review 43: 295-320.

Wu, D., Olson, D. L., and Dolgui, A. 2015. "Decision making in enterprise risk management: A review and introduction to special issue". Omega 57:1-4.

Wu, J. and Lederer, A. 2009. "A meta-analysis of the role of environment-based voluntariness in information technology acceptance”. MIS Quarterly 419-432.

Wu, T., Blackhurst, J. and Chidambaram, V. 2006. "A model for inbound supply risk analysis". Computers in Industry 57(4):350-365.

Xu, M., X. Wang, and L. Zhao. 2014. "Predicted Supply Chain Resilience Based on Structural Evolution against Random Supply Disruptions." International Journal of Systems Science: Operations and Logistics 1 (2): 105-117. 
Zsidisin, G.A. 2003. "A grounded definition of supply risk". Journal of Purchasing and Supply

Management 9(5):217-224.

Table 5. Summary of 29 studies used for meta-analysis

\begin{tabular}{|c|c|c|c|c|}
\hline Study & Constructs investigated & Sample Size & Country & Respondent's Type \\
\hline Srinivasan et al. (2011) & $\begin{array}{l}\text { PER, ENU, BSR, DER, } \\
\text { BSQ }\end{array}$ & 127 & USA & Employee \\
\hline Wagner and Bode (2008) & $\begin{array}{l}\text { PER, RMA，BSR，DER, } \\
\text { INR }\end{array}$ & 760 & Germany & Employee \\
\hline Ellinger et al. (2015) & RMA, LGP & 326 & China & Employee \\
\hline Nyamah et al. (2017) & $\begin{array}{l}\text { PER, RMA, POR, DER, } \\
\text { INR, BSR }\end{array}$ & 249 & Ghana & Employee \\
\hline Wieland et al. (2012) & $\begin{array}{l}\text { RMA, SAG, SRO, SCV, } \\
\text { PER }\end{array}$ & 270 & $\begin{array}{l}\text { Germany, Austria, } \\
\text { Switzerland }\end{array}$ & Employee \\
\hline Freise and Seuring (2015) & RMA, BER & 92 & - & Employee \\
\hline Sharma and Bhat (2016) & RMA, VIS & 79 & India & Employee \\
\hline Chen et al. (2013) & BSR, SUI, INI, CUI, PER & 203 & Australia & Employee \\
\hline Arnold et al. (2010) & $\begin{array}{l}\text { BSR,KCR, OPE, CMM, } \\
\text { QOE, PIE, CIE，BRE, } \\
\text { SIS }\end{array}$ & 207 & $\begin{array}{l}\text { China, Canada, } \\
\text { UK, India }\end{array}$ & Employee \\
\hline Kull et al. (2014) & BSR, SEX & 119 & - & Employee \\
\hline $\begin{array}{l}\text { Ouabouch and Pache } \\
\text { (2014) }\end{array}$ & $\begin{array}{l}\text { BSR, SEX, OPR, DER, } \\
\text { LGP }\end{array}$ & 165 & Morocco & Employee \\
\hline Rogers et al. (2016) & $\begin{array}{l}\text { BSR, DER, WAR, TRR, } \\
\text { LAR, NDR, INR, FIR }\end{array}$ & 104 & India & Employee \\
\hline Mishra et al. (2016) & BSR, PER & 184 & India & Employee \\
\hline Cheng et al. (2012) & BSR, PER & 192 & China & Employee \\
\hline Chen et al. (2013) & $\begin{array}{l}\text { BSR, PER, SUI, DER, } \\
\text { CUI }\end{array}$ & 203 & Australia & Employee \\
\hline Zhao et al. (2013) & INI, CUI, DER, SUI & 317 & Australia & Employee \\
\hline Fan et al. (2016) & SIS, PER & 350 & China & Employee \\
\hline Riley et al. (2016) & SIS, PER & 231 & USA & Employee \\
\hline Wiengarten et al. (2016) & SUI, CUI & 637 & Europe & Employee \\
\hline $\begin{array}{ll}\text { Braunscheidel, } & \text { and } \\
\text { Suresh (2009) } & \\
\end{array}$ & CUI, SUI & 218 & USA & Employee \\
\hline $\begin{array}{l}\text { Thomas and Gloria Penn } \\
\text { Thomas (2005) }\end{array}$ & $\begin{array}{l}\text { PEC, PET, PED, DEP, } \\
\text { PPP, SER, RAL, DEL, } \\
\text { ORC }\end{array}$ & 145 & $\overline{\text { USA }}$ & $\begin{array}{l}\text { Marketing research } \\
\text { managers }\end{array}$ \\
\hline Wagner and Bode (2006) & $\begin{array}{l}\text { DER, BSR, INR, RMA, } \\
\text { CSR, PER }\end{array}$ & 760 & Germany & Employee \\
\hline Grotsch et al. (2013) & SPA, MCS, RCS, RBS & 323 & Germany & Employee \\
\hline Kern et al. (2012) & $\begin{array}{l}\text { RID, RAS, RMI, CIP, } \\
\text { PER }\end{array}$ & 162 & Germany & Employee \\
\hline Cheng and Chen (2016) & $\begin{array}{l}\text { IOR, MOR, OBE, LOC, } \\
\text { INC }\end{array}$ & 260 & Taiwan & Employee \\
\hline Elllis et al. (2010) & $\begin{array}{l}\text { ICU, TTU, IMP, MTH, } \\
\text { PSD, ORK, ASS, MSD }\end{array}$ & 223 & USA & Employee \\
\hline Lintukangas et al. (2016) & $\begin{array}{l}\text { PRR, IBR, QUR, PCR, } \\
\text { OUR, PCR }\end{array}$ & 165 & Finland & Employees \\
\hline Fan et al. (2017) & $\begin{array}{l}\text { SSD, SCT, SSA, SIS, RAS, } \\
\text { RSM, PER, INR }\end{array}$ & 350 & China & Employees \\
\hline Speier et al. (2011) & POR, SIS, PSM, SPS & 199 & USA & Employees \\
\hline
\end{tabular}

[Note: BSR: Supply side Risk, CSR: Catastrophic Risk, CUI: Customer Integration, DER: Demand Side Risk, FIR: Financial Risk, INI: Internal Integration, INR: Logistics and Infrastructure Risk, PER: Operational Performance, POR: Political Risk, RMA: Risk Management, OPR: Operational Risk, SIS: Supply Chain Risk Information Sharing, SUI: Supplier Integration, SAG: Supply chain Agility, SRO: SC Robustness, SCV: SC Customer Value, COD: 
Competitive Differentiation, PPR: Public Policies and Institutional Related Risk, SSO: Single Sourcing, FSO: Global Sourcing, PEC: Personal commitment, PET: Personal Trust, PED: Personal Dependence, SER: Service, RAL: Rationalism, DEP: Organizational Dependence, ORC: Organizational Commitment, DEL: Delivery, MCS: Mechanistic Control System, RCS: Rational Cognitive Style, RBS: Relational buyer-supplier relationships, SPA: SCRM Proactiveness, PRR: Property Rights Risk, IBR: Image and Brand Risk, QUR: Quality Risk, PCR: Price and Cost Risk, OUR: Outsourcing Risk, SSD: SCRM Culture Diffusion, SCT: SCRM Team Support, SSA: SCRM Strategy Alignment, SIS: Risk Information Sharing, RAS: Risk Analysis and Assessment, RSM: Risk Sharing Mechanism, SOS: Supply Chain Security Information Sharing, POR: Supply Chain Security Process Management, PSM: Supply Chain Partner Security Management, SPS: Supply Chain Service Provider Security Management] 